\title{
Evaluation of geothermal gradient and heat flow distribution in Delta State, Nigeria
}

\author{
O. Anomohanran* \\ Physics Department, Delta State University, Abraka, Delta State, Nigeria. \\ *Corresponding author E-mail: mrochuko@yahoo.com
}

\begin{abstract}
Geothermal and heat flow distribution study was carried out at eighteen locations in Delta State, Nigeria using data obtained from temperature logging and thermal conductivity measurements. The result from the study showed that the geothermal gradients of the area ranged between 25.47 and $31.16{ }^{\circ} \mathrm{C} / \mathrm{km}$ while the mean geothermal gradient was obtained as $28.64{ }^{\circ} \mathrm{C} / \mathrm{km}$. This finding revealed that the geothermal gradient of the area lies within the range interval commonly encountered in tectonically inactive regions. Results also showed that the heat flow values for the area ranged between 38.93 and $89.59 \mathrm{mWm}^{-2}$ with a mean value of $62.70 \mathrm{mWm}^{-2}$. This result is an indication of an enormous energy potential which can be utilized for many purposes including electricity generation. The result further revealed that the heat flow and geothermal gradient of the study area decreases southward toward the ocean. This is an indication that fluid migration path is to the south of the study area.
\end{abstract}

Keywords: Heat flow, geothermal gradient, temperature, thermal conductivity, bottom-hole temperature.

\section{Introduction}

Geothermal gradient is referred to as the rate of increase in temperature per unit depth in the earth. It is a result of the outflow of heat from the centre of the earth [1]. According to Lowrie [1], the temperature gradient between the centre of the earth and the outer limits of the atmosphere averages about $1{ }^{\circ} \mathrm{C}$ per kilometre. Geothermal gradient is one of the most frequently used parameters in logging geophysics and are useful indicators of subsurface temperature distribution [2]. It is also useful in the estimation of geothermal resource potentials of an area and in the understanding of regional and subregional tectonics $[3,4]$.

The measurements of borehole temperature are important in several areas of underground resource investigation and management. In mineral exploration, borehole temperature measurements are useful in the detection of massive minerals. However, in hydrogeology, temperature variations can be a key element in the understanding of groundwater flow. The differential temperature curve is used to accentuate the occurrences of changes in fluid movement.

Some temperature studies in the Niger Delta area have made use of bottom-hole temperatures [5]. For instance, Akpabio and Ejedawe [6] used the linear extrapolation between ambient and bottom hole temperature to develop a geothermal gradient map of the Niger Delta. Approximate temperature at various depths in different parts of an area can be estimated from such single trend and temperature gradient maps [7]. Isotherms maps derived from geothermal studies in the Niger Delta area indicate that temperature of $150^{\circ} \mathrm{C}$ can be obtained over much of the area at depth less than $5 \mathrm{~km}[6]$.

When the depth of investigation is limited, the temperature recorded will be that of the fluid surrounding the sensor and it is a representation of the temperature of the surrounding rock formations. The subsurface temperature increases in a very irregular manner in relation to depth. On the average, it increases by $1^{0} \mathrm{C}$ for every $30 \mathrm{~m}$ [3]. This is known as the geothermal degree which varies from one place to another depending on topographic conditions, present rock types and geological history of the region.

The measured values of subsurface temperature determined from open-hole logs are always found to be lower than the true formation temperature. In the process of drilling a well, a large quantity of mud is circulated in the borehole to facilitate the drilling, evacuate the cuttings and stabilize the hole. The influence of this circulation was the reason why bottom hole temperature data was rarely used in geophysical studies in the past. Other reasons are the thermal properties of the drilling fluid, nature of heat exchange between borehole and the well, duration of drilling and non equilibrium 
temperature at the time of temperature measurements on the formation. Several methods to correct this pit fall have been proposed by many authors such as the correction made by Davies et al. [8].

It is a well established fact that temperature increases with depth in the earth. This is an indication that heat is generated inside the earth and transferred through rock and sediment layers to the surface. By assuming a linear relationship of temperature and depth, the geothermal gradient is determined. Four different methods are employed in determining thermal gradients, depending on the characteristics of primary data. These are designated as the conventional (CVL), conventional bottom temperature (CBT), aquifer temperature (AQT) and geochemical (GCL) methods [9].

Temperature distribution is one of the major factors controlling hydrocarbon generation, sediment digenesis and migration of hydrocarbons including other pore fluids [10]. The temperature distribution of the area could also be a potential source of electricity generation which will be cost effective compared to other energy sources. This study is therefore carried out to determine the geothermal gradient and heat flow distribution of the area. This will enable the various authorities to effectively monitor and harness the geothermal energy of the area for the good of all Nigerians.

\section{Materials and methods}

\subsection{The study area}

The study area is the oil rich state of Nigeria known as Delta State (fig. 1). The area is located within latitude $5.0^{0}$ to $6.0^{0} \mathrm{~N}$ and longitude $5.4^{0}$ to $6.4^{0} \mathrm{E}$ and consists mainly of thick friable sands with intercalation of clay beds, silts and coarse to fine grained sandstones [11].

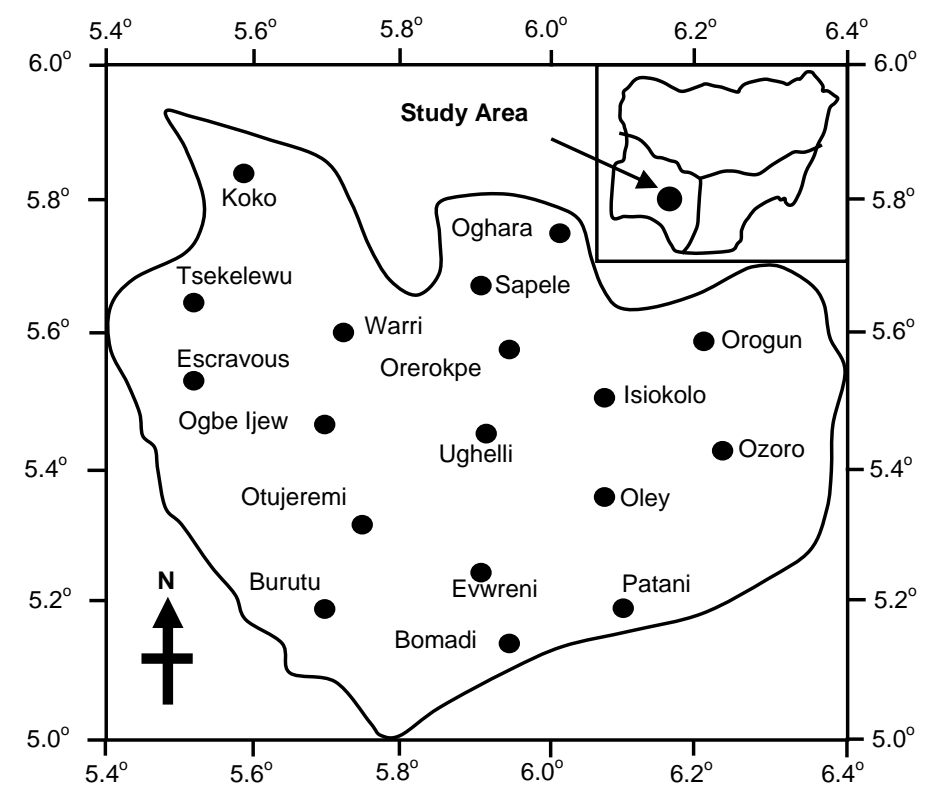

Fig. 1: Location map of the study area

\subsection{Field measurement of temperature}

Eighteen locations namely Oghara, Koko, Sapele, Tsekelewu, Warri, Escravous, Ogbe-Ijew, Otujeremi, Burutu, Bomadi, Patani, Evwreni, Oleh, Ozoro, Ughelli, Isiokoro, Orogun and Orerokpe were selected for this study (fig. 1). The procedure adopted in the measurement of temperature involves the use of the Schlumberger AMS temperature logging sonde with high sensitivity sensor known as the logging tool. The logging tool was lowered into the borehole and the temperature of various depth intervals determined in a process called continuous temperature logging method. The instrument was lowered in a slow and continuous process so that the temperatures are not altered due to agitation of the fluid when the cable and the probe pass through it. The instrument thus measured the temperature of the formation at various depth intervals. This was carried out for all eighteen wells in the study area. 


\subsection{Determination of Geothermal Gradient}

The quality consideration of the available data set are, in part, related to the characteristics of the methods used for determining gradients, which in turn depend on the nature of availability of primary temperature data. In this study, the measured temperature was plotted against the corresponding depth interval for all the wells and a linear least square fitted to the set of data $[9,12]$. The gradient of the fitting corresponds to the geothermal gradient.

\subsection{Determination of thermal conductivity}

Soil samples were collected from all eighteen wells in the study area and subjected to conductivity test in the laboratory. The determination of the thermal conductivity of the samples was carried out using the probe method. In using this method, the soil sample was placed inside a control furnace which produced the base temperature for the test. A certain amount of current was passed through the heater in the furnace for a period of time during which the temperature of the heater surface took on a characteristic form. First, the temperature rapidly rises and as the heat begins to soak in, the rate of rise becomes constant. When the thermal front reaches the outer boundary of the sample, the rise slow down and stops eventually [13]. The record of the temperature and the time was taken. From the straight line portion of the rate curve (temperature versus time), the thermal conductivity was calculated.

\subsection{Determination of heat flow}

The heat flow was determined in this study by employing the conventional method of heat flow measurements. Heat flow $\mathrm{Q}_{\mathrm{z}}$ was calculated as product of the linear least square estimate of gradient $\Delta \mathrm{T} / \Delta \mathrm{D}$ and the mean of thermal conductivity $\sigma$. The heat flow values were determined using the relation [1]:

$$
Q_{Z}=\frac{\sigma \Delta T}{\Delta D}
$$

where $\mathrm{Q}_{z}$ is the heat flow per unit area in the vertical direction, $\sigma$ is the thermal conductivity and $\frac{\Delta T}{\Delta D}$ is the geothermal gradient.

\section{Results and discussion}

The measured values of the temperature obtained from the continuous temperature logging method were plotted against the corresponding depth interval. The plots for each of the 18 wells are presented as shown in fig. 2 . The plot shows the relationship between these two parameters while the gradient of the graph gave the thermal gradient. The record of geothermal gradient, thermal conductivity and the heat flow values determined in this study are presented in Table 1. Fig. 3 is the contour map of the geothermal gradient of the area while the heat flow distribution for the area is as shown in fig. 4.

The study shows that the geothermal gradient for the area ranges from 25.47 to $31.16{ }^{0} \mathrm{C} / \mathrm{km}$. These values fall within the range interval typical of the gradients commonly encountered in tectonically inactive areas [9]. This result conforms to earlier work carried out in the Niger Delta area by Akpabio and Ejedawe [6] which shows that the thermal gradient ranges from 26.2 to $29.5{ }^{\circ} \mathrm{C} / \mathrm{km}$. The result is also in close relation with the study carried out in the northern part of Nigeria by Nwankwo et al. [14] which shows that the thermal gradient of the Chad Basin of Nigeria using bottom hole temperature method ranges from 30 to $44{ }^{0} \mathrm{C} / \mathrm{km}$. On the other hand, the heat flow for the study area ranges from 38.93 to $89.59 \mathrm{mWm}^{-2}$. This range according to the work of Gomes and Hamza [9] may be considered as typical of continental crust. This is an indication of an enormous energy potential which can be utilized for many purposes including electricity generation.

The geothermal gradient contour map shows that the thermal gradient decreases southward. The contour map of the heat flow pattern decreases from North West of the study area to a minimum at the centre and thereafter begins to increase south eastward toward the ocean. This pattern shown in the figure represents the pattern of fluid movement in the area. This fact clearly indicates that the utilization of the energy potential of the area will be optima if cited in the northern part of the study area. It also points to the fact that hydrocarbon migration path is to the south of the area. This is the reason why more wells are expected southward of the area than the northern part. 

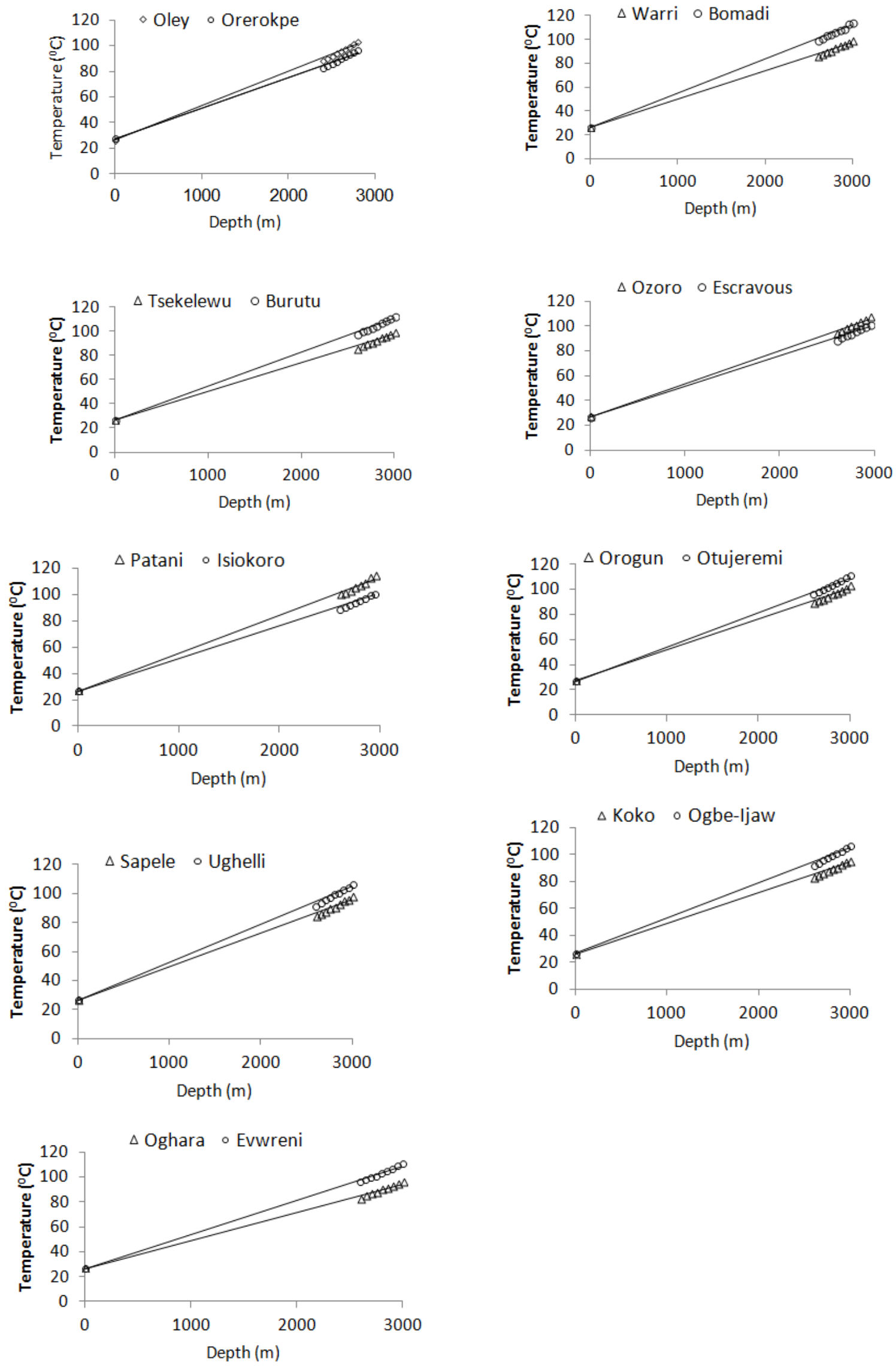

Fig. 2: Temperature variation with depth of the various wells. 


\section{Conclusion}

This work has shown that the heat flow and geothermal gradient of the study area decreases southward toward the ocean which is an indication of hydrocarbon or fluid flow direction in the area. The average geothermal gradient was obtained as $28.64{ }^{0} \mathrm{C} / \mathrm{km}$ while the mean heat flow of the area was obtained as $62.70 \mathrm{mWm}^{-2}$.

Table 1. Record of geothermal gradient and heat flow values from the various wells

\begin{tabular}{|c|c|c|c|}
\hline Location Name & $\begin{array}{l}\text { Geothermal Gradient } \\
\left({ }^{0} \mathrm{C} / \mathrm{km}\right)\end{array}$ & $\begin{array}{c}\text { Thermal Conductivity ' } K \text { ' } \\
\text { W/m } / \mathbf{m}^{-1} \mathbf{K}^{-1}\end{array}$ & $\begin{array}{c}\text { Heat Flow } \\
\text { mWm }^{-2}\end{array}$ \\
\hline Bomadi & 25.47 & 2.21 & 56.32 \\
\hline Burutu & 26.52 & 1.54 & 40.84 \\
\hline Escravous & 29.04 & 2.52 & 73.18 \\
\hline Evwreni & 27.61 & 1.41 & 38.93 \\
\hline Isiokolo & 29.11 & 2.01 & 58.51 \\
\hline Koko & 31.00 & 2.89 & 89.59 \\
\hline Ogbe Ijaw & 28.06 & 2.36 & 66.09 \\
\hline Oghara & 31.16 & 2.73 & 84.10 \\
\hline Oleh & 27.84 & 1.49 & 41.48 \\
\hline Orerokpe & 29.32 & 2.37 & 69.49 \\
\hline Orogun & 29.14 & 2.35 & 68.48 \\
\hline Otujeremi & 27.47 & 1.42 & 39.01 \\
\hline Ozoro & 27.54 & 2.14 & 58.94 \\
\hline Patani & 27.26 & 2.07 & 56.43 \\
\hline Sapele & 30.50 & 2.76 & 84.18 \\
\hline Tsekelewu & 30.18 & 2.83 & 85.41 \\
\hline Ughelli & 28.20 & 1.51 & 42.58 \\
\hline Warri & 30.17 & 2.49 & 75.12 \\
\hline
\end{tabular}

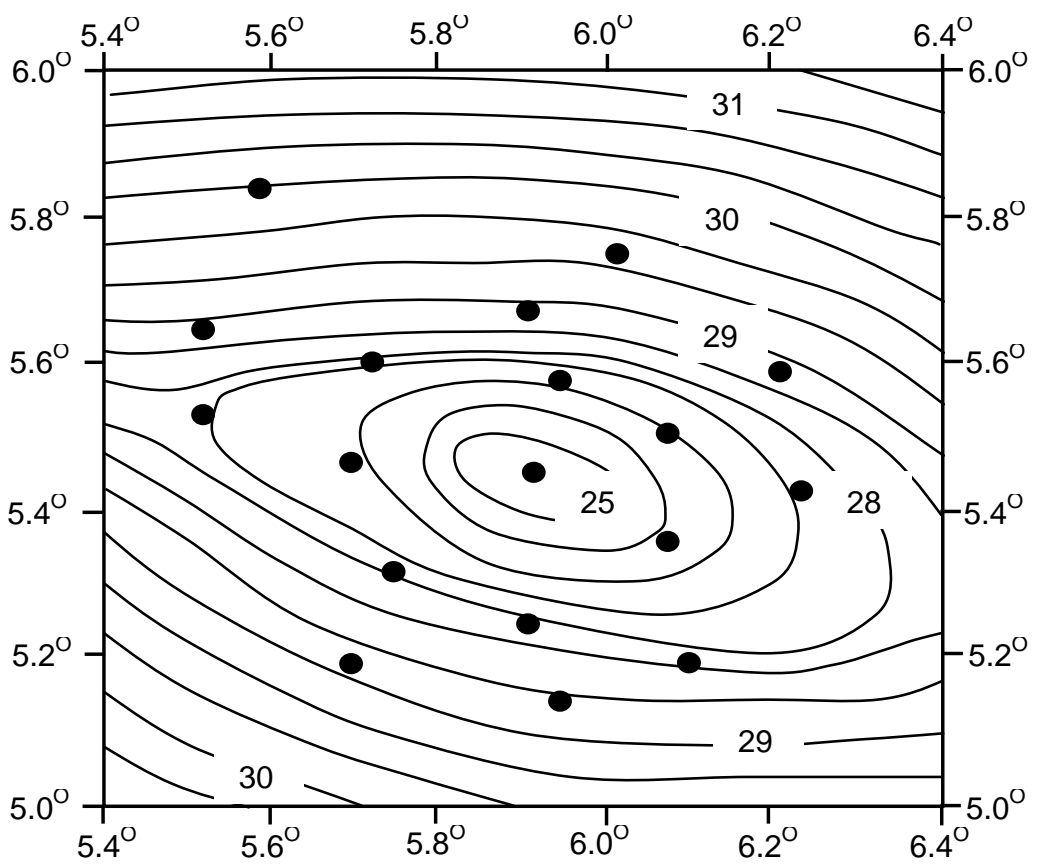

Fig. 3: Contour map showing the geothermal gradient of the area 


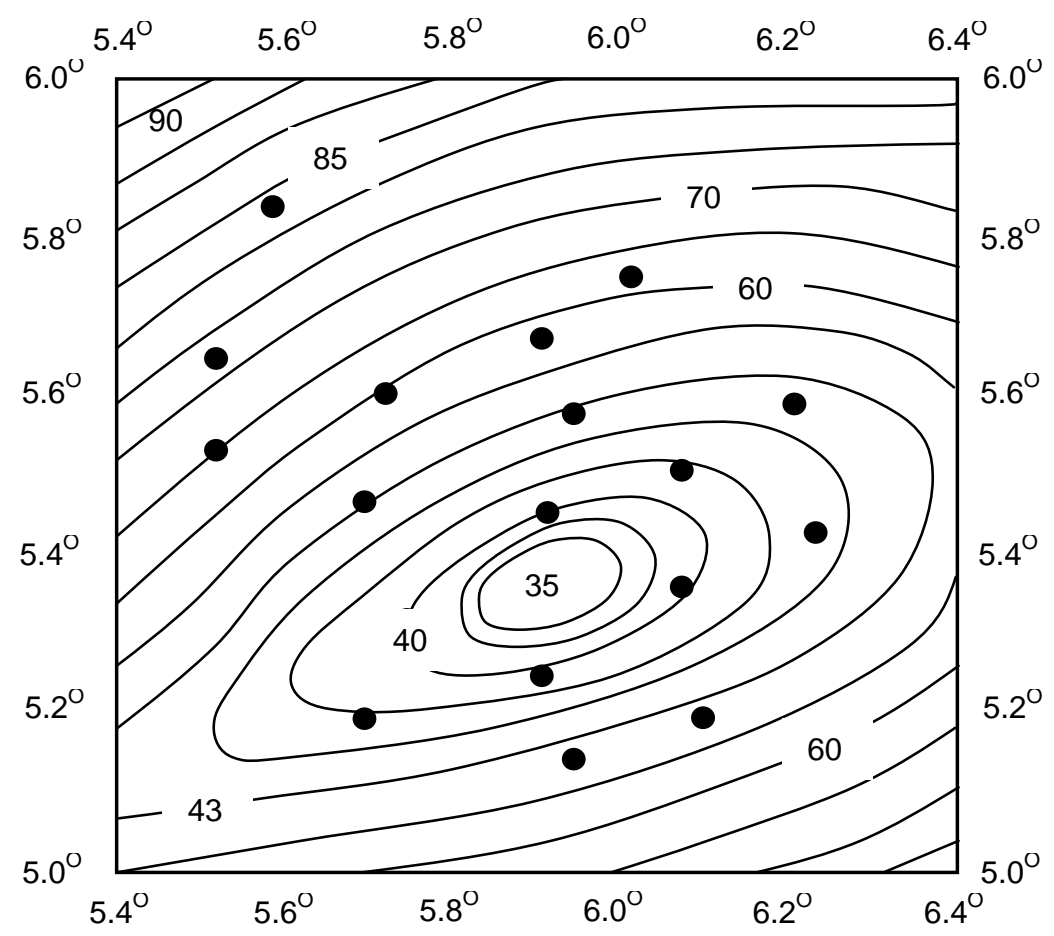

Fig. 4: Contour map showing the heat flow distribution of the area

\section{References}

[1] W. Lowrie. "Fundamentals of Geophysics," United Kingdom, Cambridge University Press, 1997.

[2] I. M. Kutasov and L. V. Eppelbaum. "Estimation of geothermal gradients from single temperature log-field cases." Journal of Geophysics and Engineering, vol. 6, no. 2, pp. 131-135, 2009.

[3] C. N. Nwankwo and A. S. Ekine. "Geothermal gradients in the Chad Basin, Nigeria, from bottom hole temperature logs." International Journal of the Physical Sciences, vol. 4, no. 12, pp. 777-783, 2009.

[4] I. M. Kutasov and L. V. Eppelbaum. "A new method for determining the formation temperature for bottom-hole temperature logs." J. Petro Gas Engr., 1(1): 001-008, 2010.

[5] S. O. Nwachukwu. "Approximate geothermal gradients in Niger Delta Sedimentary Basin." AAPG Bulletin, vol. 60, no. 7, pp. 1073-1077, 1976.

[6] I. O. Akpabio and J. E. Ejedawe. "Temperature Variations in the Niger Delta Subsurface from Continuous Temperature logs." Global J. Pure Appl. Sci., vol. 7, pp. 137-142, 2001.

[7] A. F. Bayram, S. S. Gultekin and A. R. Sogut. "Specifications of thermal waters and their classification on the base of neural method: Examples for Simav geothermal area, Western Turkey.” International Journal of the Physical Sciences, vol. 6, no. 1, pp. 43-51, 2011.

[8] M. G. Davies, D. S. Chapman, T. M. V. Wagoner and P. A. Armstrong. "Thermal Conductivity Anisotropy of Metasedimentary and Igneous Rock." J. Geophys. Res., vol. 112, B05216, 2007.

[9] J. J. Gomes and V. M. Hamza. "Geothermal gradient and heat flow in the State of Rio De Janeiro." Brazilian Journal of Geophysics, vol. 23, no. 4, pp. 325-347, 2005.

[10] F. G. Awad, P. Sibanda, M. Narayana and S. S. Motsa. "Convection from a semi-finite plate in a fluid saturated porous medium with crossdiffusion and radiative heat transfer." International Journal of the Physical Sciences. Vol. 6, no 21, pp. 4910-4923, 2011.

[11] E. E. Okwueze and A. O. Offong. "Seismic Refraction investigations of the foundation conditions of the rock/soil in parts of Akwa Ibom State of Nigeria." Journal of Physics, vol. 4, pp. 114-124, 1992.

[12] O. Anomohanran. "The use of third degree polynomial for accurate conversion of Seismic time to depth and vice versa", Journal of the Nigeria Assoc. of Mathematical Physics, vol. 8, 241-246, 2004.

[13] B. Norden and A. Forster. "Thermal conductivity and radiogenic heat production of sedimentary and magmatic rocks in the North East German Basin.” AAPG Bull., vol. 90, pp. 939-962, 2006.

[14] C. N. Nwankwo, A. S. Ekine and L. I. Nwosu. "Estimation of the heat flow variation in the Chad Basin Nigeria." J. Appl. Sci. Environ. Manage. Vol. 13, no. 1, pp. 73-80, 2009. 